\title{
Age and Smoking Predict Antibody Titres at 3 Months after the Second Dose of the BNT162b2 COVID-19 Vaccine
}

\author{
Yushi Nomura ${ }^{1,2}$, Michiru Sawahata ${ }^{1,3, * \mathbb{D}}$, Yosikazu Nakamura ${ }^{4}$, Momoko Kurihara ${ }^{1}$, Ryousuke Koike ${ }^{1,2}$, \\ Otohiro Katsube $^{1}$, Koichi Hagiwara ${ }^{3}$, Seiji Niho ${ }^{2}$, Norihiro Masuda ${ }^{5}$, Takaaki Tanaka ${ }^{6}$ and Kumiya Sugiyama ${ }^{1,7}$ (ID
}

check for updates

Citation: Nomura, Y.; Sawahata, M.; Nakamura, Y.; Kurihara, M.; Koike,

R.; Katsube, O.; Hagiwara, K.; Niho, S.; Masuda, N.; Tanaka, T.; et al. Age and Smoking Predict Antibody Titres at 3 Months after the Second Dose of the BNT162b2 COVID-19 Vaccine. Vaccines 2021, 9, 1042. https:// doi.org/10.3390/vaccines9091042

Academic Editors: Ger Rijkers and Jean-Luc Murk

Received: 6 September 2021

Accepted: 16 September 2021

Published: 18 September 2021

Publisher's Note: MDPI stays neutral with regard to jurisdictional claims in published maps and institutional affiliations.

Copyright: (c) 2021 by the authors. Licensee MDPI, Basel, Switzerland. This article is an open access article distributed under the terms and conditions of the Creative Commons Attribution (CC BY) license (https:/ / creativecommons.org/licenses/by/ $4.0 /)$.
1 Department of Respiratory Medicine and Clinical Immunology, National Hospital Organization Utsunomiya National Hospital, Utsunomiya 329-1193, Japan; uc.nomura@gmail.com (Y.N.); momoko1005kurihara@gmail.com (M.K.); ryou.k.1207@gmail.com (R.K.); 5okatsube@gmail.com (O.K.); sugiyama@dokkyomed.ac.jp (K.S.)

2 Department of Pulmonary Medicine and Clinical Immunology, Dokkyo Medical University, Shimotsuga 321-0293, Japan; siniho@dokkyomed.ac.jp

3 Division of Pulmonary Medicine, Department of Medicine, Jichi Medical University, Shimotsuke 329-0498, Japan; hagiwark@me.com

4 Department of Public Health, Jichi Medical University, Shimotsuke 329-0498, Japan; nakamuyk@jichi.ac.jp

5 Department of Surgery, National Hospital Organization Utsunomiya National Hospital, Utsunomiya 329-1193, Japan; norim0507@gmail.com

6 Department of Orthopaedic Surgery, National Hospital Organization Utsunomiya National Hospital, Utsunomiya 329-1193, Japan; tanaka.takaaki.vh@mail.hosp.go.jp

7 Department of Respiratory Medicine and Clinical Immunology, Dokkyo Medical University Saitama Medical Center, Shimotsuga 321-0293, Japan

* Correspondence: sawahata@jichi.ac.jp; Tel.: +81-285587350

Abstract: Objective: We aimed to determine antibody $(\mathrm{Ab})$ titres 3 months after the second dose of the BNT162b2 coronavirus disease-2019 (COVID-19) vaccine and to explore clinical variables predicting these titres in Japan. Methods: We enrolled 378 healthcare workers (255 women, 123 men) whose blood samples were collected $91 \pm 15$ days after the second of two inoculations of the BNT162b2 COVID-19 mRNA vaccine (Pfizer/BioNTech) given 3 weeks apart. Medical histories and demographic characteristics were recorded using a structured self-reported questionnaire. The relationships between $\mathrm{Ab}$ titres and these factors were analysed. Results: Median age (interquartile range (IQR)) of the participants was $44(32-54)$ years. Median Ab titre (IQR) against the severe acute respiratory syndrome coronavirus 2 (SARS-CoV-2) spike antigen was 764 (423-1140) U/mL. Older participants had significantly lower Ab titres; median (IQR) Ab titres were 942 (675-1390) and 1095 (741-1613) $\mathrm{U} / \mathrm{mL}$ in men and women in their 20s, respectively, but 490 (297-571) and 519 (285-761) $\mathrm{U} / \mathrm{mL}$ in men and women in their 60-70s, respectively. In the age-adjusted analysis, the only risk factors for lower $\mathrm{Ab}$ titres were male sex and smoking. However, the sex difference may have arisen from the sex difference in smoking rate. Moreover, Ab titres were significantly lower in current smokers than in ex-smokers. Conclusions: The most important factors associated with low Ab titres were age and smoking habit. In particular, current smoking status caused lower Ab titres, and smoking cessation before vaccination may improve the individual efficacy of the BNT162b2 vaccine.

Keywords: SARS-CoV-2; viral infection; clinical epidemiology

\section{Introduction}

In Japan, the BNT162b2 vaccine (Pfizer/BioNTech) was selected as the first coronavirus disease-2019 (COVID-19) mRNA vaccine to be administered to healthcare professionals, starting in February 2021. Severe acute respiratory syndrome coronavirus 2 (SARS-CoV-2) has an enveloped, single, positive-stranded RNA genome that encodes four major viral structural proteins, namely nucleocapsid (N), spike (S), envelope (E) and membrane (M) proteins; the latter three proteins are found in its membrane. The spike protein guides viral 
entry into host cells [1] by binding to ACE2 (angiotensin-converting enzyme 2), the main virus receptor, which is widely expressed on epithelial cells and macrophages [1-3] and is thus an ideal target for mRNA vaccine development [3].

Because efficacy in clinical trials and effectiveness in the community depend on the proportions of SARS-CoV-2 variants spreading in a given area, immunogenicity has attracted increasing attention as an individual index for the efficacy of COVID-19 mRNA vaccines. Humoral immunity plays major roles in protecting against and surviving SARS-CoV-2 infection $[4,5]$, and neutralising antibodies (Abs) are correlated with protection against several viruses, including SARS-CoV-2 [6-9]. However, few studies have investigated realworld $\mathrm{Ab}$ titres following vaccination with BNT162b2; focus has been placed mostly on the $\mathrm{Ab}$ status shortly after vaccination, which provides information for predicting long-term effectiveness [10-12]. These studies focused on short-term $\mathrm{Ab}$ titre data and demonstrated that lower $\mathrm{Ab}$ titres were associated with older age [10-13], male sex [10], ethnicity [14], social condition [14], obesity [15,16], smoking habit [13,16], drinking habit [10], hypertension [16], cancer [17,18], use of immunosuppressive drugs [10] and a longer period of time elapsed after vaccine inoculation $[10,16]$.

Therefore, in our preliminary study, we reported the medium-term data on $\mathrm{Ab}$ titres against the SARS-CoV-2 spike antigen produced in response to this mRNA vaccine in the Japanese population. Our results showed that the average peak titre of $2031.7 \pm 692.0 \mathrm{U} / \mathrm{mL}$ in six healthcare workers in their 50s and 60s had markedly decreased to $513.3 \pm 261.7 \mathrm{U} / \mathrm{mL}$ by 15 weeks after the second inoculation (data not shown). Here, we aimed to determine $\mathrm{Ab}$ titres against the SARS-CoV-2 spike antigen 3 months after the second dose of the BNT162b2 vaccine in 378 healthcare workers and to explore the factors associated with these $\mathrm{Ab}$ titres across a comprehensive range of clinical and lifestyle characteristics in Japan.

\section{Methods}

\subsection{Population and Study Design}

In this single-centre, prospective, observational study, we recruited healthcare workers whose blood (serum) samples were collected $91 \pm 15$ days after the second of two BNT162b2 vaccine inoculations (Pfizer/BioNTech) administered 3 weeks apart in FebruaryMarch 2021 in National Hospital Organization Utsunomiya National Hospital in Tochigi prefecture, Japan.

Initially, 381 participants were recruited, but we excluded 1 participant who received only the first dose of the BNT162b2 vaccine and 2 participants whose blood sampling confirmed the presence of Abs against SARS-CoV-2 (nucleocapsid proteins) prior to vaccination. Finally, we enrolled 378 healthcare workers ( 255 women, 123 men), including the 6 from our aforementioned preliminary study, and their medical histories and demographic characteristics were recorded using a structured self-reported questionnaire.

Blood samples collected $91 \pm 15$ days after the second inoculation were used immediately after sampling to measure total $\mathrm{Ab}$ titres against the SARS-CoV-2 spike antigen, using a commercially available electrochemiluminescence immunoassay (ECLIA) (Elecsys ${ }^{\circledR}$ AntiSARS-CoV-2 RUO; Roche Diagnostics) [19]. The relationships between Ab titres against the SARS-CoV-2 spike antigen and clinical and lifestyle characteristics were analysed.

This study was approved by the Ethics Committee of National Hospital Organization Utsunomiya National Hospital (No. 03-01, 19 April 2021). Written informed consent was obtained from all study participants before enrolment.

\subsection{Data Analysis}

Nonparametric continuous data are expressed as the median with interquartile range (IQR). Categorical data are presented as absolute numbers and relative frequencies $(n, \%)$. To calculate Spearman's rank correlation coefficient and perform the Mann-Whitney $U$ test, we used Statistical Package for the Social Sciences (SPSS version 25). 


\section{Results}

\subsection{Study Population}

In total, 378 healthcare workers ( 255 women, 123 men) were enrolled in this study. Their baseline characteristics are summarised in Table 1. Briefly, median age (IQR) of the participants was $44(32-54)$ years. Nurses $(n=177)$ and physicians $(n=38)$ comprised $56.9 \%$ of the study population.

Table 1. Baseline characteristics of participants $(N=378)$.

\begin{tabular}{|c|c|c|c|c|}
\hline Variable & Total & $\begin{array}{c}\text { Antibody Titre, } \\
\text { Median (IQR), U/mL }\end{array}$ & $\begin{array}{l}\text { Correlation } \\
\text { Coefficient } \rho \\
\end{array}$ & $p$-Value \\
\hline Age, median (IQR), y & $44(32-54)$ & & -0.386 & $<0.0001^{\#}$ \\
\hline Sex (Male/female), $n$ & $123 / 255$ & $652(388-1025) / 825(458-1210)$ & & $0.0193 *$ \\
\hline $\begin{array}{l}\text { Body mass index, median (IQR), } \\
\mathrm{kg} / \mathrm{m}^{2}\end{array}$ & $22.4(20.3-24.8)$ & & -0.007 & $0.8975^{\#}$ \\
\hline $\begin{array}{l}\text { Occupation, } n(\%) \\
\text { Physician } \\
\text { Nurse } \\
\text { Clerical work } \\
\text { Pharmacist } \\
\text { Clinical laboratory } \\
\text { technician } \\
\text { Radiologist } \\
\text { Rehabilitation staff } \\
\text { Caregiver } \\
\text { Others }\end{array}$ & $\begin{array}{c}38(10.1) \\
177(46.8) \\
34(9.0) \\
10(2.6) \\
7(1.9) \\
7(1.9) \\
18(4.8) \\
11(2.9) \\
76(20.1)\end{array}$ & $\begin{array}{l}690(550-952) \\
875(500-1240) \\
669(424-1033)\end{array}$ & & $\begin{array}{c}0.1669 \text { (vs. Nurse) * } \\
0.1015 \text { (vs. Clerical) } \\
0.7181 \text { (vs. Physician) }\end{array}$ \\
\hline $\begin{array}{l}\text { Smoking (ever/never), } n \\
\text { Brinkman index, } n\end{array}$ & $\begin{array}{c}154 / 224 \\
134 \$ \$ \$ \\
\end{array}$ & 528 (320-910)/919 (587-1373) & -0.237 & $\begin{array}{l}<0.0001 * \\
0.0062^{\#}\end{array}$ \\
\hline Drinking, $n$ & $235 / 140 / 3 \S$ & $758(418-1175) / 823(471-1133) \S \S$ & & $0.7244^{*}$ \\
\hline $\begin{array}{l}\text { Allergy, } n \\
\text { Food } \\
\text { Drug }\end{array}$ & $\begin{array}{l}40 / 302 / 36^{\S} \\
38 / 303 / 37 \S\end{array}$ & 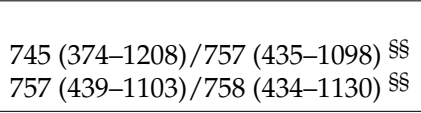 & & $0.8223^{*}$ \\
\hline $\begin{array}{l}\text { Allergic disease, } n \\
\text { Allergic rhinitis including pollinosis } \\
\text { Bronchial asthma } \\
\text { Skin allergy including atopic dermatitis }\end{array}$ & $\begin{array}{l}178 / 176 / 24 \S \\
46 / 308 / 24 \S \\
49 / 305 / 24 \S\end{array}$ & $\begin{array}{l}780(385-1138) / 696(446-1103) \$ \S \\
876(449-1135) / 742(418-1133) \S \S \\
924(582-1410) / 733(415-1080) \$ \S\end{array}$ & & $\begin{array}{l}0.7839^{*} \\
0.5095^{*} \\
0.0413^{*}\end{array}$ \\
\hline Diabetes mellitus, $n$ & $12 / 353 / 13^{\S}$ & $382(211-741) / 768(436-1150) \S \S$ & & $0.0189 *$ \\
\hline Hypertension, $n$ & $27 / 338 / 13 \S$ & $521(285-869) / 777(443-1158) \S \S$ & & $0.0120 *$ \\
\hline Dyslipidaemia, $n$ & $18 / 347 / 13^{\S}$ & $569(340-878) / 768(434-1155) \S \S$ & & $0.0741 *$ \\
\hline Collagen disease, $n$ & $13 / 345 / 20 \S$ & $548(256-1030) / 766(435-1140) \S \S$ & & $0.3170 *$ \\
\hline
\end{tabular}

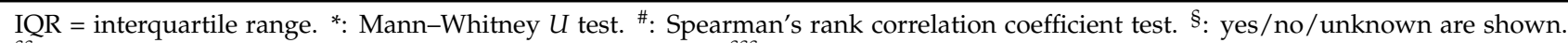
§\&: Antibody titres are shown for yes/no, excluding unknown. $\$ \&$ : ever smoking only.

3.2. Distribution of Ab Titres against SARS-CoV-2 Spike Antigen 3 Months after Vaccination According to Age and Sex

Median Ab titre (IQR) against the SARS-CoV-2 spike antigen was 764 (423-1140) U/mL (Table 1). Older participants were found to have significantly lower SARS-CoV-2 Ab titres (correlation coefficient $\rho=-0.386, p<0.0001$ ) (Figure 1). The Ab titres in both men and women tended to decrease with an increase in age from 20s to 70s (Figure 2). Median (IQR) $\mathrm{Ab}$ titres of men in their 20s, 30s, 40s, 50s and 60s-70s were 942 (675-1390), 821 (484-1115), 710 (393-938), 449 (289-861) and 490 (297-571) U/mL, respectively. Median (IQR) Ab titres of women in their 20s, 30s, 40s, 50s and 60s-70s were 1095 (741-1613), 991 (613-1410), 827 (501-1150), 685 (377-1035) and 519 (285-761) U/mL, respectively. Men in each age group tended to have lower median Ab titres than those of women in the same age group, although the differences were not significant (Figure 2). 


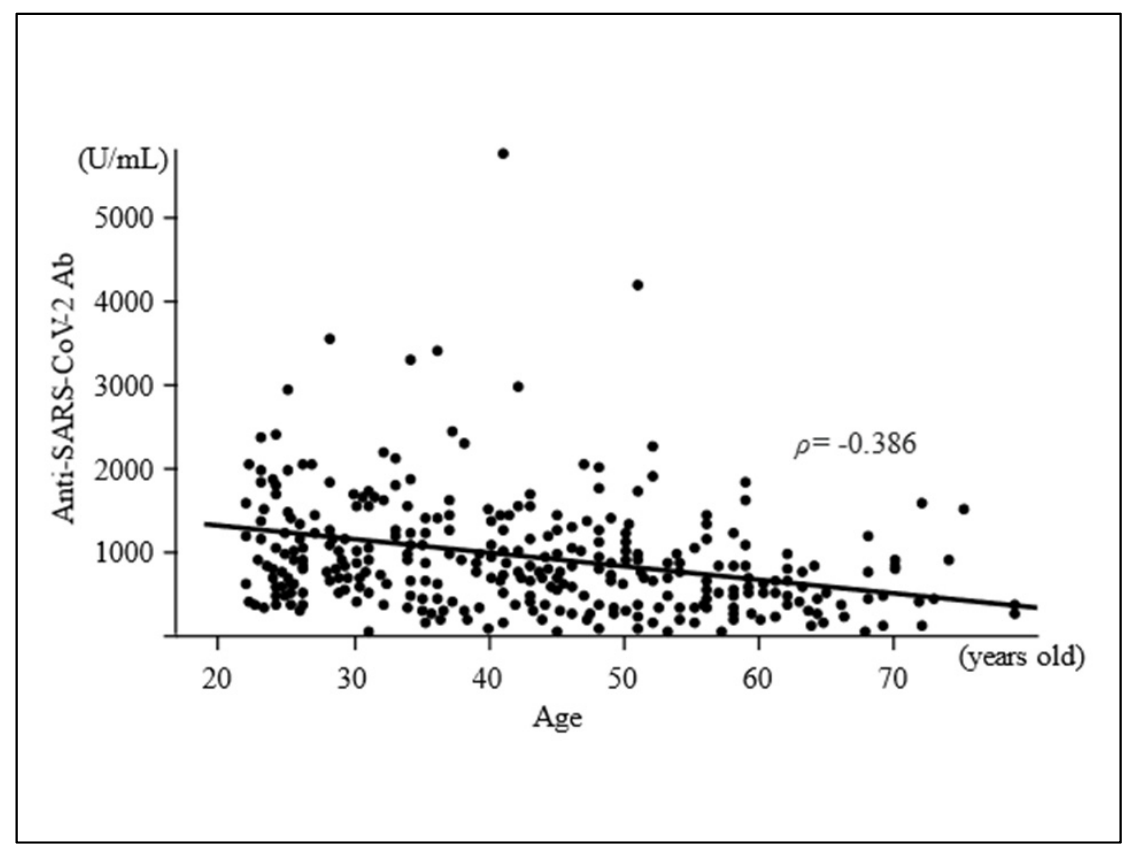

Figure 1. Scatter plot of the distribution of antibody titres according to age. Median antibody titre (IQR) against the SARS-CoV-2 spike antigen was 764 (423-1140) U/mL. Older participants had significantly lower SARS-CoV-2 antibody titres (correlation coefficient $\rho=-0.386$ ).

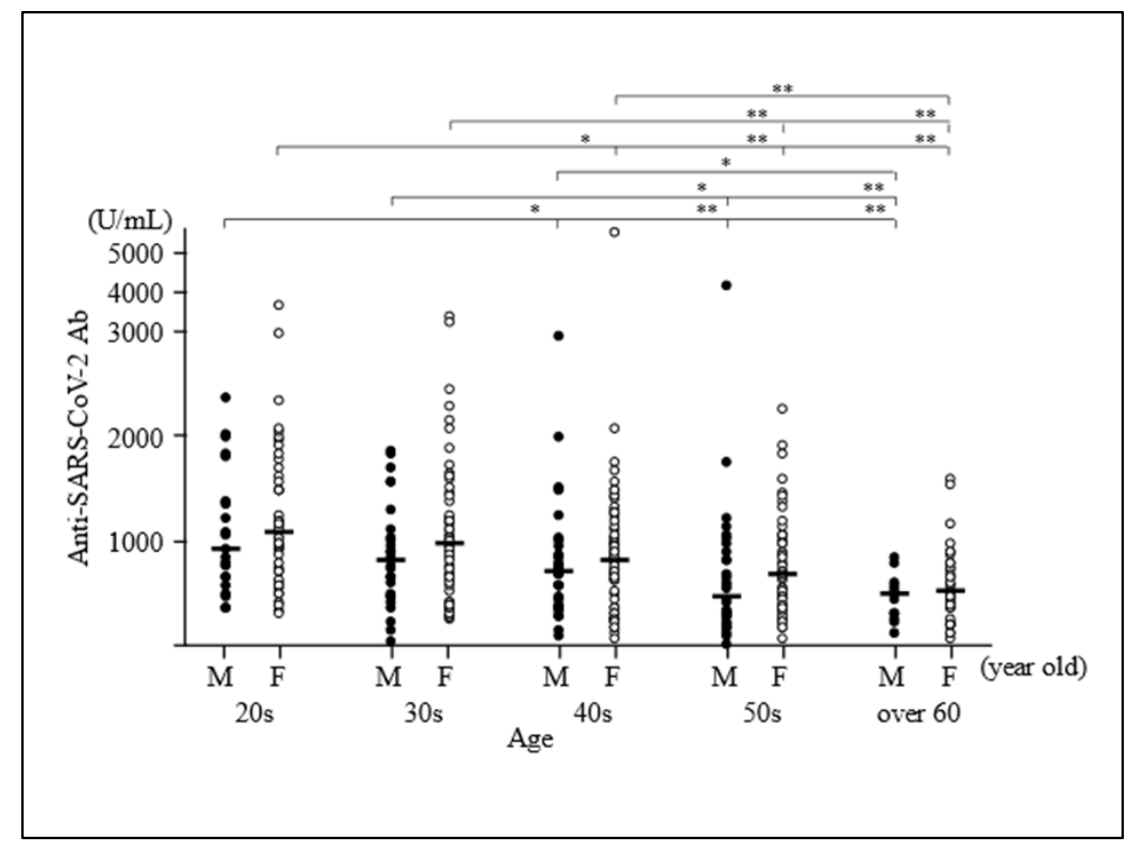

Figure 2. Distribution of antibody titres according to age group and sex. Antibody titres in both men and women tended to decrease as participants' ages increased from their 20s to 70s. Median (IQR) antibody titres of men in their 20s, 30s, 40s, 50s and 60s-70s were 942, 821, 710, 449 and $490 \mathrm{U} / \mathrm{mL}$, respectively. Median (IQR) antibody titres of women in their 20s, 30s, 40s, 50s and 60s-70s were $1095,991,827,685$ and $519 \mathrm{U} / \mathrm{mL}$, respectively. Men in each age group tended to have lower median antibody titres than women in the same age group. ${ }^{*} p<0.05,{ }^{* *} p<0.01$.

\subsection{Relationship between Ab Titres against SARS-CoV-2 Spike Antigen 3 Months after} Vaccination and Risk Factors

We first performed univariate analyses to identify factors associated with serum $\mathrm{Ab}$ titres against the SARS-CoV-2 spike protein. The factors significantly associated with a 
lower $\mathrm{Ab}$ titre were older age, male sex, smoking, skin allergy (including atopic dermatitis), diabetes mellitus and hypertension (Table 1).

We also analysed the risk factors for lower $\mathrm{Ab}$ titres after adjustment for age, because the prevalence of the factors may differ according to age, such as hypertension. In the age-adjusted analysis, individual $\mathrm{Ab}$ titres were recalculated by means of subtraction of the median $\mathrm{Ab}$ titres according to corresponding age groups. Median $\mathrm{Ab}$ titres of participants in their 20s, 30s, 40s, 50s and 60s-70s were 1050, 931, 779, 619 and $491 \mathrm{U} / \mathrm{mL}$, respectively. For example, an age-adjusted $\mathrm{Ab}$ titre in a participant in their 20s was calculated as follows: "an individual Ab titre-1050". After age adjustment, the only factors significantly associated with lower Ab titres were male sex and smoking (Table 2). In terms of smoking, age-adjusted median Ab titres (IQR) were -174 ( -378 to 145$)$ and 90 ( -174 to 512 ) in ever smokers and never smokers, respectively.

Table 2. Age-adjusted data of median antibody titres $(N=378)$.

\begin{tabular}{|c|c|c|c|c|}
\hline Variable & Total & $\begin{array}{c}\text { Antibody Titre, } \\
\text { Median (IQR), U/mL }\end{array}$ & $\begin{array}{l}\text { Correlation } \\
\text { Coefficient } \rho\end{array}$ & $p$-Value \\
\hline Male/female & $123 / 255$ & $-69(-373$ to 216$) / 55$ ( -266 to 426$)$ & & 0.0170 * \\
\hline $\begin{array}{l}\text { Occupation, } n(\%) \\
\text { Physician } \\
\text { Nurse } \\
\text { Clerical work }\end{array}$ & $\begin{array}{c}38(10.1) \\
177(46.8) \\
34(9.0)\end{array}$ & $\begin{array}{l}31(-263 \text { to } 144) \\
46(-335 \text { to } 440) \\
-91(-309 \text { to } 301)\end{array}$ & & $\begin{array}{c}0.6069 \text { (vs. Nurse) }{ }^{*} \\
0.5018 \text { (vs. Clerical) } \\
0.7479 \text { (vs. Physician) * }\end{array}$ \\
\hline $\begin{array}{l}\text { Smoking (ever/never), } n \\
\text { Brinkman index }\end{array}$ & $\begin{array}{c}154 / 224 \\
134 \$ \$ \$\end{array}$ & $-174(-378$ to 145$) / 90$ (-174 to 512$)$ & -0.003 & $\begin{array}{l}<0.0001 * \\
0.97010^{*}\end{array}$ \\
\hline Drinking, $n$ & $235 / 140 / 3 \S$ & $-18(-329$ to 371$) / 32(-267$ to 318$) \S \S$ & & $0.4955^{*}$ \\
\hline $\begin{array}{l}\text { Allergy, } n \\
\text { Food } \\
\text { Drug }\end{array}$ & $\begin{array}{l}40 / 302 / 36^{\S} \\
38 / 303 / 37 \S\end{array}$ & $\begin{array}{c}36(-393 \text { to } 357) /-7(-296 \text { to } 319) \S \S \\
114(-165 \text { to } 317) /-15(-309 \text { to } 320) \S \S\end{array}$ & & $\begin{array}{l}0.7336^{*} \\
0.3018^{*}\end{array}$ \\
\hline $\begin{array}{l}\text { Allergic disease, } n \\
\text { Allergic rhinitis including pollinosis } \\
\text { Bronchial asthma } \\
\text { Skin allergy including atopic dermatitis }\end{array}$ & $\begin{array}{l}178 / 176 / 24 \S \\
46 / 308 / 24^{\S} \\
49 / 305 / 24^{\S}\end{array}$ & $\begin{array}{l}10(-334 \text { to } 331) /-19(-289 \text { to } 320) \S \S \\
93(-324 \text { to } 329) /-23(-303 \text { to } 321) \$ \$ \\
129(-257 \text { to } 522) /-28(-308 \text { to } 299) \$ \S\end{array}$ & & $\begin{array}{l}0.8541 * \\
0.6102 * \\
0.0826^{*}\end{array}$ \\
\hline Diabetes mellitus, $n$ & $12 / 353 / 13 \S$ & $-169(-315$ to 82$) / 0(-300$ to 342$) \S \S$ & & $0.3105^{*}$ \\
\hline Hypertension, $n$ & $27 / 338 / 13 \S$ & $-88(-361$ to 284$) / 0$ ( -286 to 338$) \S \S$ & & 0.3771 * \\
\hline Dyslipidaemia, $n$ & $18 / 347 / 13 \S$ & $24(-280$ to 114$) /-3(-300$ to 340$) \S \S$ & & $0.7484 *$ \\
\hline Collagen disease, $n$ & $13 / 345 / 20^{\S}$ & $-90(-516$ to 252$) / 0(-299$ to 334$) \S \S$ & & $0.3085 *$ \\
\hline
\end{tabular}

IQR = interquartile range. *: Mann-Whitney $U$ test. \#: Spearman's rank correlation coefficient test. ${ }^{\S}$ : yes/no/unknown are shown. $\$ \S$ : Antibody titres are shown for yes/no, excluding unknown. ${ }^{\S}$ : ever smoking only.

To analyse the observed sex difference, we divided the participants into ever smokers and never smokers. In both the male and female groups, age-adjusted median Ab titres were significantly lower in ever smokers than in never smokers; age-adjusted median $\mathrm{Ab}$ titres (IQR) in men were $-246(-398$ to 65$)$ and $49(-186$ to 621$)$ in ever smokers and never smokers, respectively, while those in women were -140 ( -304 to 217$)$ and 95 ( -151 to 503$)$ in ever smokers and never smokers, respectively. However, in both the ever smoker and never smoker groups, no significant sex differences in age-adjusted median Ab titres were observed (Table 3). Given that the smoking rates in the male and female groups were $61.0 \%$ and $31.0 \%$, respectively, these results suggest that the sex difference in Ab titres strongly reflects sex differences in smoking, rather than biological sex differences. In addition, $\mathrm{Ab}$ titres were significantly lower in current smokers than in ex-smokers (Table 4). These results suggest that smoking cessation will reduce the risk of a lower $\mathrm{Ab}$ titre. 
Table 3. Age-adjusted median antibody titres in ever smokers vs. never smokers.

\begin{tabular}{lccc}
\hline & $\begin{array}{c}\text { Male, Antibody Titre, } \\
\text { Median (IQR), U/mL }\end{array}$ & $\begin{array}{c}\text { Female, Antibody Titre, } \\
\text { Median (IQR), U/mL }\end{array}$ & $p$-Value between Sexes \\
\hline Ever smokers (men, 75; women, 79) & $-246(-398$ to 65) & $-140(-304$ to 217) & $0.1175 *$ \\
\hline Never smokers (men, 48; women, 176) & $49(-186$ to 621) & $95(-151$ to 503) & $0.9970 *$ \\
\hline$p$-value between ever and never smokers & $0.0007 *$ & $0.0023 *$ & \\
\hline \multicolumn{4}{c}{ IQR = interquartile range. *: Mann-Whitney $U$ test. }
\end{tabular}

Table 4. Age-adjusted median antibody titres in ever smokers: current smokers vs. ex-smokers.

\begin{tabular}{lcc}
\hline & $\begin{array}{c}\text { Antibody Titre, } \\
\text { Median (IQR), U/mL }\end{array}$ & $\begin{array}{c}p \text {-Value } \\
\text { (vs. Never Smokers) }\end{array}$ \\
\hline Current smokers $(n=49)$ & $-271(-475$ to 33) & $<0.0001 *$ \\
\hline Ex-smokers $(n=91)$ & $-162(-332$ to 285$)$ & $0.0019^{*}$ \\
\hline P-value (current vs. ex-smokers) & $0.0188^{*}$ & \\
\hline
\end{tabular}

$\mathrm{IQR}=$ interquartile range. *: Mann-Whitney $U$ test.

\section{Discussion}

To our knowledge, this is the first study to report real-world Ab titres against the SARS$\mathrm{CoV}-2$ spike antigen at 3 months after vaccination and to identify the factors associated with these $\mathrm{Ab}$ titres across a comprehensive range of clinical and lifestyle characteristics in Japan. Three important findings were obtained. First, median age (IQR) of the participants was 44 (32-54) years, median Ab titre (IQR) against the SARS-CoV-2 spike antigen was 764 (423-1140) U/mL, and older participants had significantly lower Ab titres, with median (IQR) Ab titres of $942(675-1390)$ and 1095 (741-1613) U/mL in men and women in their 20s, respectively, but 490 (297-571) and 519 (285-761) U/mL in men and women in their 60 s-70s, respectively. Second, in the age-adjusted analysis, the only risk factors for lower $\mathrm{Ab}$ titres were male sex and smoking. However, the sex difference may have arisen from the sex difference in smoking rate. Other health complications, including diabetes mellitus and allergic diseases, were not correlated with lower $\mathrm{Ab}$ titres after age adjustment. Third, $\mathrm{Ab}$ titres were significantly lower in current smokers than in ex-smokers. Smoking cessation can thus be expected to reduce the risk of lower $\mathrm{Ab}$ titres.

Because the efficacy of COVID-19 mRNA vaccines in clinical trials and their effectiveness in the community depend on the proportions of SARS-CoV-2 variants spreading in a given area, immunogenicity has attracted increasing attention as an individual index for the efficacy of these vaccines. Neutralising Abs are correlated with protection against SARS-CoV-2 [5], but only a few studies have investigated real-world Ab titres following vaccination with BNT162b2, focusing instead on Ab status shortly after vaccination. Those studies demonstrated that lower Ab titres may be caused by older age [10-13], male sex [10], ethnicity [14], social condition [14], obesity [15,16], smoking habit [13,16], drinking habit [10], hypertension [16], cancer [17,18], use of immunosuppressive drugs [10] and a longer period of time elapsed after vaccine inoculation $[10,16]$. Medium-term data of serological $\mathrm{Ab}$ titres in response to the BNT162b2 vaccine are urgently needed, as are the clinical and lifestyle factors predicting these titres.

Concerning our first main finding, the median titre in individuals shortly after a full vaccination schedule of this vaccine in Japan was reported to be $2060 \mathrm{U} / \mathrm{mL}$ (IQR, 1250-2650) [10], which is similar to the median titre reported from Italy $(1975 \mathrm{U} / \mathrm{mL}$; IQR, 895-3455) [20]. However, Ab titres against the SARS-CoV-2 spike antigen following vaccination cannot currently predict the likelihood of developing COVID-19. Our Ab titres 3 months after the second inoculation ranged from 3 to $5790 \mathrm{U} / \mathrm{mL}$, and the median $\mathrm{Ab}$ titre (IQR) was $764(423-1140) \mathrm{U} / \mathrm{mL}$, which was much lower than the above-mentioned value obtained shortly after the second inoculation, reflecting the reported association between a longer period of time elapsed since the second inoculation and lower $\mathrm{Ab}$ titres. 
Moreover, older participants had significantly lower SARS-CoV-2 Ab titres. Indeed, in our preliminary study with six participants in their 50 s and 60 s, the average peak titre of $2031.7 \pm 692.0 \mathrm{U} / \mathrm{mL}$ had markedly decreased to $513.3 \pm 261.7 \mathrm{U} / \mathrm{mL}$ by 15 weeks after the second inoculation (data not shown). Two of the six subjects had Ab titres of $220.0 \mathrm{U} / \mathrm{mL}$, which is a similar level to that observed immediately before the second inoculation, suggesting that the third vaccination with COVID-19 mRNA vaccine may need to be added, at least in part, for people over 50 years old in Japan. Although sufficient clinical efficacy of the BNT162b2 vaccine against most of the conventional SARS-CoV-2 variants was observed even after 6 months without $A b$ titre data [21], the clinical efficacy of a single inoculation with this vaccine against the SARS-CoV-2 Delta variant has been reported to be only $30.7 \%$ [22].

Concerning our second main finding, various reports have demonstrated that our participants receiving immunosuppressive drugs also seemed to have low Ab titres, including a man in his 30s taking infliximab [13] with a titre of $9.0 \mathrm{U} / \mathrm{mL}$, a woman in her 40 s taking etanercept with $258 \mathrm{U} / \mathrm{mL}$ and a woman in her 30s taking etanercept with $415 \mathrm{U} / \mathrm{mL}$. In our study, smoking was the most impactful factor, and the sex difference in Ab titres was at least partly due to smoking. To clarify the effects of smoking, we performed additional analyses. However, the Brinkman index and the number of cigarettes per day did not influence the $\mathrm{Ab}$ titres. Thus, smoking itself is a risk factor for low $\mathrm{Ab}$ titres, rather than the duration of smoking or number of cigarettes per day. Moreover, smoking cessation can be expected to effectively increase $\mathrm{Ab}$ titres because they were significantly lower in current smokers than in ex-smokers. On the other hand, another study reported that alcohol was the most impactful lifestyle factor, not smoking [10]. Although the authors of that study do not show age-adjusted data, their conclusions were different from ours. Their results were based on analysis of samples collected 2-5 weeks after the second dose of the vaccine. In contrast, our samples were obtained 3 months after the second dose. One hypothesis is that alcohol may affect $\mathrm{Ab}$ production, whereas smoking may lead to decreases in the level of Abs after they are produced. In addition, we believe that an age-adjusted analysis is critical. To clarify the reason for the difference between that study and ours, we need to analyse longitudinal data to observe changes in $\mathrm{Ab}$ titres over time, and we are planning such an additional study. Although the mechanisms are not known, previous studies have reported an association between a smoking habit and lower Ab titres against both influenza virus [23] and hepatitis B virus [24] following vaccination.

Some limitations and possible sources of bias in this study include the following: Firstly, the participants were limited in number and were all healthcare workers vaccinated at a single national hospital in Tochigi prefecture, where the COVID-19 pandemic has been well-controlled since SARS-CoV-2 began spreading around the globe. Therefore, the results obtained in this study might not be generalisable on a wide scale, or even within Japan. Secondly, several data, including body height and weight, were obtained by means of a standardised structured self-reported questionnaire. We cannot deny the possibility that some data may have been affected by recall bias. Third, the cut-off level of the $\mathrm{Ab}$ against the SARS-CoV-2 spike antigen needs to be determined for the different variants of SARS-CoV-2, but this information is currently unavailable. Further studies are needed to confirm our observations.

In conclusion, we have reported, for the first time, real-world $\mathrm{Ab}$ titres against the SARS-CoV-2 spike antigen at 3 months after the second dose of the BNT162b2 vaccine, which were much lower than those measured shortly after the second inoculation. We demonstrated that the most important factors associated with low Ab titres were age and smoking habit. In particular, current smoking status causes lower Ab titres, and smoking cessation before vaccination may improve the individual effectiveness of the BNT162b2 vaccine. To establish a more personalised approach to vaccination involving earlier boosters, different schedules or different types of vaccines, further studies are necessary regarding the associations between $\mathrm{Ab}$ titres and the comprehensive medical histories of individuals. 
Author Contributions: Conceptualisation, M.S., K.S., Y.N. (Yushi Nomura) and Y.N. (Yosikazu Nakamura); methodology and software, Y.N. (Yushi Nomura), K.S., M.S. and Y.N. (Yosikazu Nakamura); validation, K.S., M.S. and Y.N. (Yosikazu Nakamura); formal analysis and investigation, K.S., Y.N. (Yushi Nomura), M.S. and Y.N. (Yosikazu Nakamura); resources, T.T., K.S., N.M., Y.N. (Yushi Nomura), M.S., O.K., R.K. and M.K.; data curation, Y.N. (Yushi Nomura), K.S. and M.S.; writing-original draft preparation, M.S., K.S., Y.N. (Yushi Nomura) and Y.N. (Yosikazu Nakamura); writing-review and editing, T.T., N.M., S.N., K.H., O.K., R.K. and M.K.; visualisation, K.S., Y.N. (Yushi Nomura) and M.S.; supervision, M.S., K.S., T.T., S.N. and K.H.; project administration, K.S. and T.T.; funding acquisition, T.T. and K.S. All authors have read and agreed to the published version of the manuscript.

Funding: This research received no external funding.

Institutional Review Board Statement: The study was conducted according to the guidelines of the Declaration of Helsinki and approved by the Ethics Committee of National Hospital Organization Utsunomiya National Hospital (No. 03-01, 19 April 2021).

Informed Consent Statement: Informed consent was obtained from all subjects involved in the study.

Acknowledgments: The authors thank all staff at National Hospital Organization Utsunomiya National Hospital for providing support during sample collection. We would like to thank Miwa Okada, Minako Yamagishi, Junko Shibayama, Yuko Tajima, Mami Ochiai, Midori Takahashi, Hiroko Ueno, Natsuka Suzuki and Yoshino Iwaya for providing support during data analysis.

Conflicts of Interest: The authors declare no conflict of interest.

\begin{abstract}
Abbreviations
COVID-19: coronavirus disease 2019; SARS-CoV-2: severe acute respiratory syndrome coronavirus 2; Ab: antibody; IQR: interquartile range.
\end{abstract}

\title{
References
}

1. Song, Z.; Xu, Y.; Bao, L.; Zhang, L.; Yu, P.; Qu, Y.; Zhu, H.; Zhao, W.; Han, Y.; Qin, C. From SARS to MERS, Thrusting Coronaviruses into the Spotlight. Viruses 2019, 11, 59. [CrossRef]

2. Hoffmann, M.; Kleine-Weber, H.; Schroeder, S.; Krüger, N.; Herrler, T.; Erichsen, S. SARS-CoV-2 Cell Entry Depends on ACE2 and TMPRSS2 and Is Blocked by a Clinically Proven Protease Inhibitor. Cell 2020, 181, 271-280. [CrossRef] [PubMed]

3. Jiang, S.; Lu, L.; Liu, Q.; Xu, W.; Du, L. Receptor-binding domains of spike proteins of emerging or re-emerging viruses as targets for development of antiviral vaccines. Emerg. Microbes Infect. 2012, 1, e13. [CrossRef] [PubMed]

4. Dispinseri, S.; Secchi, M.; Pirillo, M.F.; Tolazzi, M.; Borghi, M.; Brigatti, C.; de Angelis, M.L.; Baratella, M.; Bazzigaluppi, E.; Venturi, G.; et al. Neutralizing antibody responses to SARSCoV-2 in symptomatic COVID-19 is persistent and critical for survival. Nat. Commun. 2021, 12, 2670. [CrossRef]

5. Lumley, S.F.; O’Donnell, D.; Stoesser, N.E.; Matthews, P.C.; Howarth, A.; Hatch, S.B.; Marsden, B.D.; Cox, S.; James, T.; Warren, F.; et al. Antibody Status and Incidence of SARS-CoV-2 Infection in Health Care Workers. N. Engl. J. Med. 2021, 384, 533-540. [CrossRef] [PubMed]

6. Miyakawa, K.; Jeremiah, S.S.; Kato, H.; Yamaoka, Y.; Go, H.; Yamanaka, T.; Ryo, A. Rapid detection of neutralizing antibodies to SARS-CoV-2 variants in post-vaccination sera. medRxiv 2021. [CrossRef]

7. Plotkin, S.A. Correlates of protection induced by vaccination. Clin. Vaccine Immunol. 2010, 17, 1055-1065. [CrossRef]

8. Iyer, A.S.; Jones, F.K.; Nodoushani, A.; Kelly, M.; Becker, M.; Slater, D.; Mills, R.; Teng, E.; Kamruzzaman, M.; Garcia-Beltran, W.F.; et al. Dynamics and significance of the antibody response to SARS-CoV-2 infection. medRxiv 2020. [CrossRef]

9. Chen, R.E.; Zhang, X.; Case, J.B.; Winkler, E.S.; Liu, Y.; VanBlargan, L.A.; Liu, J.; Errico, J.M.; Xie, X.; Suryadevara, N.; et al. Resistance of SARS-CoV-2 variants to neutralization by monoclonal and serum-derived polyclonal antibodies. Nat. Med. 2021, 27, 717-726. [CrossRef] [PubMed]

10. Kageyama, T.; Ikeda, K.; Tanaka, S.; Taniguchi, T.; Igari, H.; Onouchi, Y.; Kaneda, A.; Matsushita, K.; Hanaoka, H.; Nakada, T.; et al. Antibody responses to BNT162b2 mRNA COVID-19 vaccine in 2015 healthcare workers in a single tertiary referral hospital in Japan. medRxiv 2021. [CrossRef]

11. Müller, L.; Andrée, M.; Moskorz, W.; Drexler, I.; Walotka, L.; Grothmann, R.; Ptok, J.; Hillebrandt, J.; Ritchie, A.; Rabl, D.; et al. Age-dependent immune response to the Biontech/Pfizer BNT162b2 COVID-19 vaccination. Clin. Infect. Dis. 2021. [CrossRef]

12. Terpos, E.; Trougakos, I.P.; Apostolakou, F.; Charitaki, I.; Sklirou, A.D.; Mavrianou, N.; Papanagnou, E.-D.; Liacos, C.-I.; Gumeni, S.; Rentziou, G.; et al. Age-dependent and gender-dependent antibody responses against SARS-CoV-2 in health workers and octogenarians after vaccination with the BNT162b2 mRNA vaccine. Am. J. Hematol. 2021, 96, E257-E259. [CrossRef] [PubMed] 
13. Kennedy, N.A.; Lin, S.; Goodhand, J.R.; Chanchlani, N.; Hamilton, B.; Bewshea, C.; Nice, R.; Chee, D.; Cummings, J.F.; Fraser, A.; et al. Infliximab is associated with attenuated immunogenicity to BNT162b2 and ChAdOx1 nCoV-19 SARS-CoV-2 vaccines in patients with IBD. Gut 2021, 70, 1884-1893. [CrossRef]

14. Wei, J.; Stoesser, N.; Matthews, P.C.; Ayoubkhani, D.; Studley, R.; Bell, I.; Bell, J.I.; Newton, J.N.; Farrar, J.; Diamond, I.; et al. COVID-19 Infection Survey team. Antibody responses to SARS-CoV-2 vaccines in 45,965 adults from the general population of the United Kingdom. Nat. Microbiol. 2021, 6, 1140-1149. [CrossRef] [PubMed]

15. Ledford, H. How obesity could create problems for a COVID vaccine. Nature 2020, 586, 488-489. [CrossRef]

16. Watanabe, M.; Balena, A.; Tuccinardi, D.; Tozzi, R.; Risi, R.; Masi, D.; Caputi, A.; Rossetti, R.; Spoltore, M.E.; Filippi, V.; et al. Central obesity, smoking habit, and hypertension are associated with lower antibody titres in response to COVID-19 mRNA vaccine. Diabetes Metab. Res. Rev. 2021, e3465. [CrossRef]

17. Collier, D.A.; Ferreira, I.A.T.M.; Kotagiri, P.; Datir, R.P.; Lim, E.Y.; Touizer, E.; Meng, B.; Abdullahi, A.; Elmer, A.; Kingston, N.; et al. Age-related immune response heterogeneity to SARS-CoV-2 vaccine BNT162b2. Nature 2021, 596. [CrossRef]

18. Monin-Aldama, L.; Laing, A.G.; Muñoz-Ruiz, M.; McKenzie, D.R.; del Molino del Barrio, I.; Alaguthurai, T.; Domingo-Vila, C.; Hayday, T.S.; Graham, C.; Cooper, J.; et al. Interim results of the safety and immune-efficacy of 1 versus 2 doses of COVID-19 vaccine BNT162b2 for cancer patients in the context of the UK vaccine priority guidelines. medRxiv 2021. [CrossRef]

19. Perkmann, T.; Perkmann-Nagele, N.; Breyer, M.K.; Breyer-Kohansal, R.; Burghuber, O.C.; Hartl, S.; Aletaha, D.; Sieghart, D.; Quehenberger, P.; Marculescu, R.; et al. Side-by-side comparison of three fully automated SARS-CoV-2 antibody assays with a focus on specificity. Clin. Chem. 2020, 66, 1405-1413. [CrossRef] [PubMed]

20. Callegaro, A.; Borleri, D.; Farina, C.; Napolitano, G.; Valenti, D.; Rizzi, M.; Maggiolo, F. Antibody response to SARS-CoV-2 vaccination is extremely vivacious in subjects with previous SARS-CoV-2 infection. J. Med. Virol. 2021, 93, 4612-4615. [CrossRef] [PubMed]

21. Pfizer. Pfizer and BioNTech Confirm High Efficacy and No Serious Safety Concerns Through Up to Six Months Following Second Dose in Updated Topline Analysis of Landmark COVID-19 Vaccine Study. Available online: https: / /www.pfizer.com/news / press-release/press-release-detail/pfizer-and-biontech-confirm-high-efficacy-and-no-serious (accessed on 15 June 2021).

22. Lopez Bernal, J.; Andrews, N.; Gower, C.; Gallagher, E.; Simmons, R.; Thelwall, S.; Stowe, J.; Tessier, E.; Groves, N.; Dabrera, G.; et al. Effectiveness of Covid-19 Vaccines against the B.1.617.2 (Delta) Variant. N. Engl. J. Med. 2021, 385. [CrossRef] [PubMed]

23. MacKenzie, J.S.; MacKenzie, I.H.; Holt, P.G. The effect of cigarette smoking on susceptibility to epidemic influenza and on serological responses to live attenuated and killed subunit influenza vaccines. J. Hyg. 1976, 77, 409-417. [CrossRef] [PubMed]

24. Zimmermann, P.; Curtis, N. Factors that influence the immune response to vaccination. Clin. Microbiol. Rev. 2019, 32, e00084-18. [CrossRef] [PubMed] 